\title{
LONG SEGMENT VERSUS SHORT SEGMENT FIXATION WITH INDEX LEVEL IN THORACOLUMBAR BURST FRACTURE
}

\section{Mohamed Adel Kamal Mohamed Abdeen, Omar Mohamed Abdel Wahab Kelany, Amr Mohamed El Adawy, Tarek Abdel Samad El Hewala Orthopedic Surgery department Faculty of Medicine, Zagazig University}

\begin{abstract}
Background The goal of this study is to compare the results of long segment fixation versus short segment fixation with index level.

Methods Fifty patients were enrolled in two groups twenty five patients each. First group was treated by long segment fixation. Second group was treated by short segment fixation with index level screw.

Results This was found to be statistically significant comparing between long segment fixation group with short segment with index level group regarding mean intraoperative blood loss, mean operative time and mean incision length. At the final follow it was found that the mean LKA preoperatively, after 3months and 6 months postoperatively was statistically insignificant.

Conclusion The results of short segment fixation with index level are encouraging and comparable to those of long segment fixation regard correction of local kyphotic angle with less motion segments fixation in short segment group.

Keywords: Thoracolumbar . Spine . Long segment fixation. Short segment fixation with index level Corresponding author Name: Mohamed Adel Kamal Mohamed Abdeen Tel:01066745113 Email: mabdeen575@gmail
\end{abstract}

\section{INTRODUCTION}

$\mathbf{T}$ he thoracolumbar region is one of the most common regions for spine injures (about 90\%), burst fractures comprise about $10-20 \%$ of such injuries ${ }^{[1]}$. Burst fractures mainly occur in association with motor vehicle accidents and fall from height ${ }^{[2]}$.

A burst fracture is characterized by displacement or rotation of the posterior cortex of the vertebral body, compressing the spinal canal and altering the stability of spine $^{[2]}$.

Most authors agree that surgical treatment is necessary for unstable burst fractures [3]. Surgical intervention can decompress neural elements, restore the height of the vertebral body, correct and prevent angular deformity, promote stability of the spine, allowing early mobilization and promoting neurological improvement ${ }^{[4]}$.

Posterior instrumentation is recommended, based on the excellent results achieved in terms of stability of the spine, anatomical alignment, postoperative neurological improvement and low patient morbidity ${ }^{[5]}$. Numerous pedicular fixation methods through a posterior approach have been described. One of the main differences between them is the number of fixed segments ${ }^{[6]}$.

Short fixations, with fewer stabilized and fused uninjured segments, can preserve the maximum thoracolumbar movement. This type of fixation involve pedicle screw placement one level above and one level below the injured segment and by adding intermediate screw at the fractured vertebrae stiffer construct can be gained ${ }^{[7]}$.

Long segment fixation with pedicle screws and rods two levels above and below the fracture level provide good fixation; however, increasing length of posterior fusion segment should be considered carefully especially in the more mobile segments of the lumbar spine ${ }^{[8]}$.

\section{PATIENTS AND METHODS}

This is a both prospective and retrospective study comparing outcome of 
surgical treatment of patients with thoracolumbar burst fracture. Fifty patients were enrolled in two groups twenty five patients each. First group was treated by long segment fixation. Second group was treated by short segment fixation with index level screw. The retrospective study was performed on thirty patients with thoracolumbar burst fracture from 2014 to 2016. The prospective study was performed on twenty patients with thoracolumbar burst fracture from 2016 to 2018. The neurological status of the patient was recorded based on the ASIA score. Plain spinal $\mathrm{x}$-ray and computed tomography were used to evaluate the fracture. All fractures were classified based on AOSpine thoracolumbar spine injury classification system (Burst type A3-A4)

All operations were performed using the same instrumentation system. Usually partial reduction is achieved when the patient is placed to the prone position on a special frame. Indirect decompression was done by countering the rod that corrects kyphosis and recreates normal lordosis, distraction and reduction maneuvers can be applied to aid in reduction of compression via ligamentotaxis. Patients were followed for 6 months. Different parameters were used to compare the two groups, including the duration of operation incision length, blood loss and local kyphotic angle.

Comparisons between measures (Mean \pm SD) of two groups were done using student t-test for unpaired data and using paired t-test for paired data, while comparisons between measures (Mean $\pm \mathrm{SD}$ ) between multiple groups were done by one way ANOVA test for Statistical analysis. The test results were considered significant when $\mathrm{P}$. value $<0.05$.

\section{RESULTS}

\section{Operative Data}

This was found to be statistically significant comparing between (LSF) group with (SSFIS) group regarding mean intraoperative blood loss, mean operative time and mean incision length. (Table 1) Regarding mean intraoperative radiation exposure this was found to be statistically insignificant comparing between (LSF) group with (SSFIS) group. (Table 1)

Table (1): Mean \pm SD \& Median of intraoperative blood loss, operative time, radiation exposure \& incision length for both groups

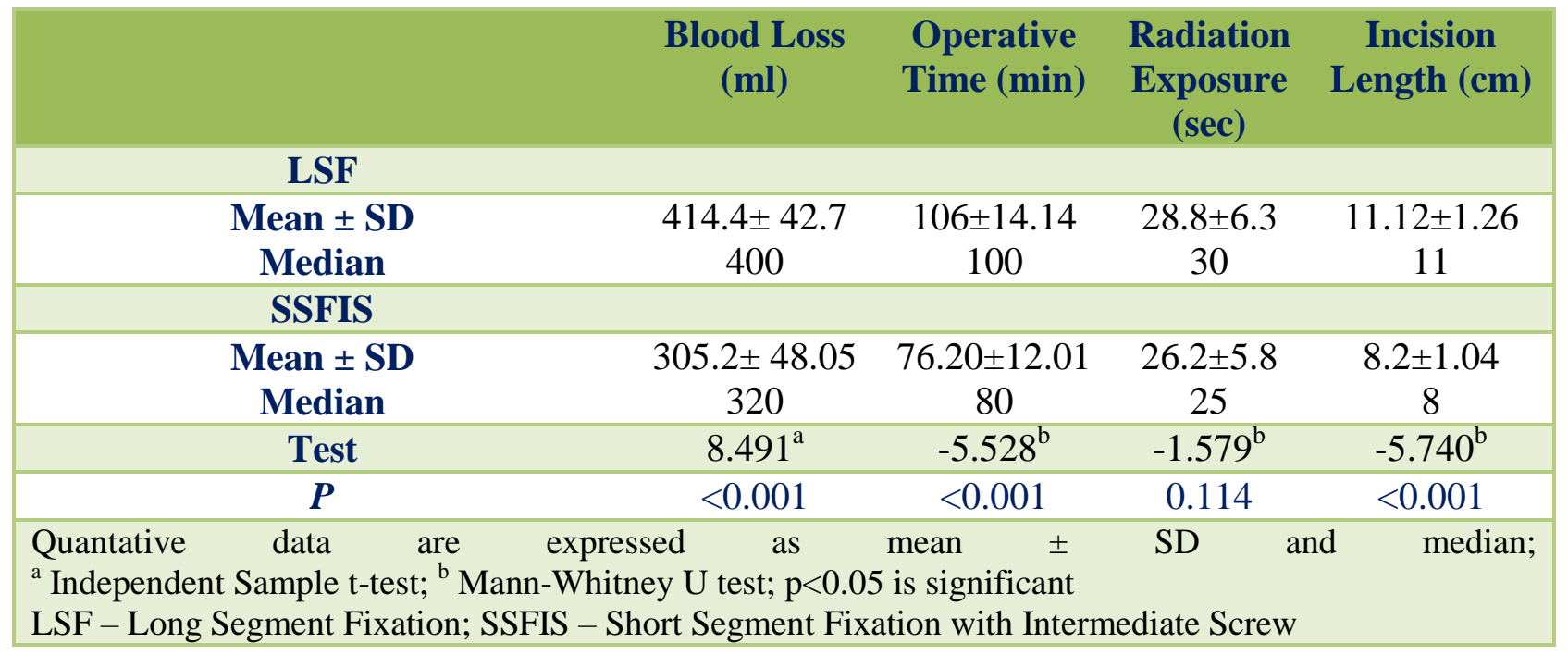

$\underline{\text { Radiological results: }}$

Local kyphotic angle (LKA) 
In long segment fixation (LSF) group, the mean local kyphotic angle preoperatively was $14.20^{\circ}( \pm 2.06)$ improved after three months postoperatively to be $1.72^{\circ}( \pm 0.89)$, at the final follow up the mean local kyphotic angle was $2.16^{\circ}( \pm 0.98)$, and this was found to be statistically significant $(\mathrm{p}<0.001)$. (Table 2) In short segment fixation with intermediate screw (SSFIS) group, the mean local kyphotic angle preoperatively was $14.48( \pm 1.53)$ improved after three months postoperatively to be $1.76^{\circ}( \pm 1.01)$, at the final follow up the mean local kyphotic angle was $2.16^{\circ}( \pm 1.06)$, and this was found to be statistically significant $(\mathrm{p}<0.001)$. (Table 2) In comparison of radiological results between two groups, it was found that the mean LKA preoperatively, after 3months and 6 months postoperatively was statistically insignificant. (Table 2)

Table (2): Mean \pm SD \& Median of (LKA) preoperative, 3 months and 6 months post operatively for both groups

\begin{tabular}{|c|c|c|c|c|c|}
\hline & Preoperative & 3 month & Final & Test & P \\
\hline LSF & & & & & \\
\hline $\begin{array}{c}\text { Mean } \pm \text { SD } \\
\text { Median }\end{array}$ & $14.20 \pm 2.06$ & $1.72 \pm 0.89$ & $2.16 \pm 0.98$ & $45.364^{\mathrm{a}}$ & $<0.001$ \\
\hline SSFIS & 14.00 & 1.74 & 2.00 & & \\
\hline Mean \pm SD & $14.48 \pm 1.53$ & $1.76 \pm 1.01$ & $2.16 \pm 1.06$ & $45.624^{\mathrm{a}}$ & $<0.001$ \\
\hline Median & 15.00 & 2.00 & 2.00 & & \\
\hline Test & $-0.713^{\mathrm{b}}$ & $-0.203^{\mathrm{b}}$ & $-0.020^{\mathrm{b}}$ & & \\
\hline p & 0.476 & 0.839 & 0.984 & & \\
\hline
\end{tabular}

COMPLICATION

In long segment fixation group two patients $(8 \%)$ developed wound infection, one presented with superficial infection was treated by antibiotics and repeated dressing. The other patient presented with deep infection was treated by debridement.

In short segment fixation group one patient (4\%) developed wound infection, was treated by antibiotics and repeated dressing.

\section{DISCUSSION}

Posterior fixation has become a popular method in the treatment of thoracolumbar burst fractures especially after the introduction of transpedicular screws. McLain et al [9] studied segmental transpedicular instrumentation and stated that it allowed immediate mobilization of thoracolumbar injured patients, eliminating thromboembolic and pulmonary complications, and reducing overall morbidity and mortality. But, the number of levels to be fixed to gain maximum reduction and stability in treating thoracolumbar burst fractures is still an issue of debate.

Several biomechanical studies were done to evaluate the index level fixation stability. These studies confirmed the superiority of short segment fixation with intermediate screws constructs over the conventional short segment constructs. It had been shown that application of fractured level screws decreased the stresses on the superior and inferior pedicle screws in the construct (Robert P. Norton ${ }^{[10]}$, Qin-Liang Li ${ }^{[11]}$ ) In the cadaveric study of Mahar et al ${ }^{[7]}$, where they used short segmental fixation with screws inserted in the fractured vertebra. They concluded that fixation of burst fractures with screws at the level of the fracture offers improved biomechanical 
stability especially against axial torsion. Data obtained from these studies suggested that the use of intermediate screws provides the advantages of a stiffer construct, an increased biomechanical stability and the effect of 3-point fixation of the fractured segment leading to a better pulled-out strength.

Theoretically, decreasing the number of fixed levels (one level above and below the fracture) will decrease the incision length, blood loss and operative time. This was the condition in this study when short segment construct with index level fixation when compared to long segment construct. Also, it was found that applying additional screws in the fractured vertebra neither increased the operative time nor the blood loss. Scheer et al ${ }^{[12]}$ conducted a systematic literature review to analysis the level of evidence in the management of the traumatic thoracolumbar burst fracture across 20 years of evidence and they reported that there is high level of evidence for short and long segment fixation without fusion in these cases. Also, they mentioned that long segment fixation there are more operative time, blood loss and longer hospitalization than short segment.

The most common radiological parameter used to study the effectiveness of treatment is the local kyphotic angle. Alvine et al. ${ }^{[13]}$ reported that use of long segment fixation lengthen the lever arm of the construct enhancing the stability and allowing effective reduction of kyphotic deformity. It had shown in this study that radiological results (LKA) were comparable between two groups with no significant statistical difference after 3 and 6 months postoperatively (LKA $p=0.839$ and 0.984 ) so reduction of kyphosis was achieved and maintained in both groups.

Farrokhi et al ${ }^{[14]}$ and Guven et al ${ }^{[15]}$, conducted randomized controlled trials to compare the results better conventional short segment stabilization and that with the index level fixation and they concluded that inclusion of the fracture level into the construct has offered better kyphosis correction, in addition to fewer instrument failures, without additional complications and with comparable if not better clinical and functional outcome than conventional short segment fixation which supports our assumption.

\section{CONCLUSION}

- The results of short segment fixation with index level are encouraging. It gives good results as regard correction of local kyphotic angle after six months follow up and preserve more motion segments than long segment fixation.

- $\quad$ The results of long segment fixation are good as regards correction of local kyphotic angle but it takes more operative time, larger amount of blood loss and bigger incision length than short segment.

\section{REFERENCES}

1. Alanay A, Acaroglu E, Yazici M, et al. Short-segment pedicle instrumentation of thoracolumbar burst fractures: does transpedicular intracorporeal grafting prevent early failures. Spine 2001; 26:213-217.

2. Dai LY, Jiang SD, Wang XY, et al. A review of the management of thoracolumbar burst fractures. SurgNeurol 2007; 67:221-231.

3. Kim HS, Lee SY, Nanda A, Kim JY, Park JO, Moon SH, et al. Comparison of surgical outcomes in thoracolumbar fractures operated with posterior constructs having varying fixation length with selective anterior fusion. Yonsei Med J. 2009; 50(4):546-54.

4. Akalm S, Kiş M, Benli IT, Citak M, Mumcu EF, Tüzüner M. Results of the AO spinal internal fixator in the surgical treatment of thoracolumbar burst fractures. Eur Spine J.1994; 3(2):102-6.

5. Parker JW, Lane JR, Karaikovic EE, Gaines RW. Successful short-segment instrumentation and fusion for thoracolumbar 
spine fractures: a consecutive 41/2-year series. Spine 2000; 25(9):1157-70.

6. Katonis PG, Kontakis GM, Loupasis GA, Aligizakis AC, Christoforakis JI, Velivassakis EG. Treatment of unstable thoracolumbar and lumbar spine injuries using Cotrel-Dubousset instrumentation.Spine. 1999; 24(22):2352-

7. Mahar A, Kim C, Wedemeyer $M$, Mitsunaga L, Odell T, Johnson B, Garfin S. Short-segment fixation of lumbar burst fractures using pedicle fixation at the level of the fracture. Spine 2007; 32:1503-7.

8. Berllbara C, Mirza SK, Chapman JR. Surgical treatment of thoracolumbar fractures: posterior approach. In: Reitman CA (ed) management of Thoracolumbar Fractures. AAOS, Rosemont 2004; 65-78.

9. Mclain RF. Functional outcomes after surgery for spinal fractures: return to work and activity. Spine. 2004; 29(4):470-7.

10. Robert P. Norton, Edward L. Milne, David N. Kaimrajh, Frank J. Eismont, Loren L. Latta, Seth K. Williams. Biomechanical analysis of four- versus sixscrew constructs for short-segment pedicle screw and rod instrumentation of unstable thoracolumbar fractures. The Spine Journal 14 (2014) 1734-1739.

11. Qin-liang Li, Xiu-Zhong Li, Yi Liu, Husheng Zhang, Peng Shang, Zhao-ming
Chu, Jin-chuan Chen, Ming Chen, Rujie Qin. Treatment of thoracolumbar fracture with pedicle screws at injury level: a biomechanical study based on threedimensional finite element analysis. Eur $\mathbf{J}$ Orthop Surg Traumatol (2013) 23:775-780.

12. Scheer K. Justin, Jashua Bakhsheshian, Shayan Fakurnejad. Evidence-Based medicine of traumatic thoracolumbar burst fractures: A systematic review of operative management across 20 years. Global Spine J .2005 Feb; 5(1):73-82.

13. Alvine GF, Swain JM, Asher MA, Burton DC. Treatment of thoracolumbar burst fractures with variable screw placement or Isola instrumentation and arthrodesis: case series and literature review. J Spinal Disord Tech. 2004; 17: 251-64.

14. Farrokhi Reza Majid, Ali Razmkon, Zohreh Maghami, Zahra Nikoo. Inclusion of the fracture level in short segment fixation of thoracolumbar fractures. Eur Spine $\mathbf{J}$ (2010) 19:1651-1656.

15. Guven Osman, Baris Kocaoglu, Murat Bezer, Nuri Aydin, Ufuk Nalbantoglu. The Use of Screw at the Fracture Level in the Treatment of Thoracolumbar Burst Fractures. J Spinal Disord Tech Volume 22, Number 6, August 2009. 